\title{
A review on the evidence of transgenerational transmission of posttraumatic stress disorder vulnerability
}

\author{
Seyyed Taha Yahyavi, ${ }^{1}$ Mehran Zarghami, ${ }^{1}$ Urvashi Marwah ${ }^{2}$ \\ ${ }^{1}$ Department of Psychiatry, Psychiatry and Behavioral Sciences Research Center, Mazandaran University of Medical Sciences, Sari, Iran. \\ ${ }^{2}$ Medical University of the Americas, Charlestown, Saint Kitts and Nevis.
}

\begin{abstract}
Objective: To understand the risks of posttraumatic stress disorder (PTSD) development in the next generation of PTSD patients, we conducted a review on the biological, but not genetic, evidence of transgenerational transmission of PTSD vulnerability.

Methods: Pertinent articles published from 1985 to September 2011 were searched using online academic search engines, including MEDLINE, EMBASE, ScienceDirect, OVID, PsycLIT, and SCOPUS, and a non-systematic review was conducted.

Results: There is paradoxical evidence that hypothalamic-pituitary-adrenal axis changes in PTSD patients may also be evident in their offspring. This effect and biological vulnerability to PTSD may be transmitted across generations through maternal epigenetic programming during pregnancy. The samples of most studies, which were not large enough and represented the outcome of few research groups, consisted of a specific type of patients with a particular trauma.

Conclusions: There is still a need to conduct studies in other geographical areas with different genetic background and larger samples considering different types of trauma other than those specified in the current literature, so as to strengthen the evidence of transgenerational transmission of PTSD vulnerability.
\end{abstract}

Keywords: Posttraumatic stress disorder; biological markers; neuroendocrinology; stress; violence/aggression

\section{Introduction}

Posttraumatic stress disorder (PTSD) is a psychopathological response to an extraordinary stressor characterized by three clusters of categorical symptoms for at least 1 month: 1) intrusive re-experiencing of the trauma; 2) persistent avoidance of stimuli associated with the trauma; and 3) persistent symptoms of increased physiological and psychological arousal ${ }^{1,2}$ with prominent anxiety and depressive features. ${ }^{3-5}$ PTSD can appear at any age, including at childhood. ${ }^{6}$ It is estimated that as much as $14 \%$ of the population will develop this condition at some point during their lives. ${ }^{7,8}$ However, a higher lifetime PTSD prevalence of around $30 \%$ has been reported for Vietnam veterans and female victims of rape in retrospective epidemiological studies. ${ }^{9,10}$ This figure was reported as $34 \%$ in burn survivors. ${ }^{11}$

Essential elements in developing PTSD are a severe trauma and a personal vulnerability. ${ }^{12}$ The factors that affect these elements can change the final outcome. If the person is not vulnerable, even a very severe trauma will not result in PTSD; conversely, a vulnerable person will

Correspondence: Mehran Zarghami, Professor of Psychiatry, Zare Hospital, Neka Road, Postal code 4815466848, Sari, Mazandaran, Iran.

E-mail: mzarghami@mazums.ac.ir

Submitted Sep 08 2012, accepted May 162013. express PTSD symptoms when faced with trauma not usually severe enough to trigger PTSD. Some indices of traumatic events include their type (e.g., combat, rape, and car accident), duration (chronic vs. acute), and severity, as well as intention. ${ }^{13,14}$ It seems that the prominence of some features (tonic or baseline signs and symptoms, especially avoidance and emotional numbness, vs. phasic or episodic signs and symptoms, especially re-experience) may affect the prognosis of vulnerable individuals. ${ }^{15}$

The vulnerability of a person to develop PTSD is a complex process. Two major components of vulnerability that may influence each other are psychological and biological factors. Psychological vulnerability refers to the structure of personality traits such as defense mechanisms, the strength of ego, cognitive schema, etc. ${ }^{16}$ Biological factors refer to modulation of biological elements such as the autonomic nervous system and hormonal and neurotransmitter patterns.

Although some components of vulnerability to PTSD are acquired, there is also evidence that other components may be transferred from progenitors to the next generation. ${ }^{16-18}$ One of the core biological features which probably contribute to the transmission of PTSD vulnerability to offspring is related to changes in the hypothalamic-pituitary-adrenal (HPA) axis. Observations of low cortisol levels in PTSD date back many years. ${ }^{19,20}$ In 
some studies, attenuation of the acute cortisol response to trauma due to previous traumatization has been reported to contribute to the development of PTSD. ${ }^{21,22}$ These findings hypothesize that reduced cortisol levels at the time of trauma may compromise the inhibition of stress-induced biological responses, resulting in prolonged physiological and emotional distress, which would then facilitate the development of PTSD in individuals at risk. ${ }^{23}$ Hence, understanding the risks of its development in the next generation is important.

Herein, we conduct a review on the biological - but not genetic - evidence of transgenerational transmission of PTSD vulnerability, and make suggestions for future studies. Understanding the evidence and probable pathways should guide us to new perspectives for preventing PTSD development in the next generation by monitoring or even controlling factors implicated in this vulnerability.

\section{Methods}

In this narrative unsystematic review, relevant studies were identified by searching the MEDLINE, EMBASE, ScienceDirect, OVID, PsycLIT, and SCOPUS databases for articles published from 1985 to September 2011. The primary keywords for the search were posttraumatic stress disorder, PTSD, offspring, next generation, and trauma. Because of the recurrence of some words in the title of articles produced by this query, we decided to include them in the search as secondary keywords to avoid missing relevant studies. These words were Holocaust, intergenerational effect, risk factors, genetic, epigenetic, and cortisol. Letters to the editors and case reports were not included. The search was performed by repeated use of the words in different combinations. Given the breadth of knowledge and the need to focus on topics of interest, we decided to confine our study to nongenetic biological evidence. Therefore, all studies directly related to evidence of non-genetic biological transmission of PTSD vulnerability to the next generation were included. Thereafter, the related citations and reference lists of the obtained articles were checked for further relevant articles, and some additional publications were included using this approach.

The definition of PTSD was based on DSM-III, DSM-IIIR, DSM-IV, or DSM-IV-TR criteria. Studies reporting subthreshold/partial PTSD, animal studies, and/or those published in a language other than English and Persian were excluded.

A number of limitations to the current review should be acknowledged. First, because of the novelty and complexity of the subject and the limitations of the included studies, beside the variety of their methods, we did not conduct a systematic review or meta-analysis. Second, we have limited this review to published English or Persian reports and have not sought to identify unpublished works or those in other languages. Third, as the nature of the data permits only a narrative summary, the process of data abstraction from the papers was not done blind, hence leaving room for bias.

\section{Results}

Biological evidence of the intergenerational transmission of PTSD vulnerability has a long and interesting history.

\section{Cortisol levels in offspring of PTSD patient}

After establishing the hormonal change in PTSD patients, it was time to focus on a hormonal profile of the offspring. Several studies have been conducted on the second generation of survivors of the Nazi genocide. Researchers examined mean 24-h urinary cortisol excretion in 11 offspring of Holocaust survivors (OHS) with no parents suffering from PTSD and the mean 24-h urinary cortisol level in OHS whose parents suffered from PTSD, compared to 15 demographically similar offspring of Jews born to parents who did not undergo the trauma of the genocide. Low cortisol levels were significantly associated with both PTSD in parents and lifetime PTSD in subjects. Moreover, offspring with both parental PTSD and lifetime PTSD had the lowest cortisol levels of all study groups. ${ }^{24}$ These data were reanalyzed along with four new subjects to examine the relationship between cortisol and severity of PTSD symptoms in offspring and their parents, revealing significant negative correlations between severity of parental PTSD and offspring urinary cortisol excretion. ${ }^{25}$ Alterations in the hormonal profile of OHS with PTSD were later reexamined by serum cortisol measurement ${ }^{26}$ and the dexamethasone suppression test (DST). ${ }^{27}$ This analysis showed lower serum cortisol levels and greater cortisol suppression in OHS with parental PTSD than in OHS without parental PTSD or comparator subjects. In these studies, the relationship between hormonal profile alterations and parental PTSD was maintained or strengthened after considering the contribution of childhood trauma.

\section{Role of childhood trauma}

Association between childhood trauma and PTSD was also examined in 51 adult $\mathrm{OHS}$ and 41 comparator subjects, taking into consideration parental trauma exposure and parental PTSD. It was concluded that adult OHS significantly express higher levels of self-reported childhood trauma, particularly emotional abuse and neglect. ${ }^{28}$ As expected, the mean urinary cortisol level was lower in individuals reporting emotional abuse than in those without a history of emotional abuse. Hence, the experience of childhood trauma may be an important factor in the transmission of PTSD from parent to child. $^{28,29}$ This notion indicated that traumatized parents would express improper behavior toward their offspring during a critical developmental window, and that such behavior may have long-lived effects on glucocorticoid regulation in the offspring. ${ }^{30}$

\section{Beyond the role of childhood trauma}

The collapse of the World Trade Center (WTC) on September 11, 2001 allowed researchers to study the relationship between maternal PTSD and PTSD in infant 
offspring. Hence, the effect of traumatic experiences in childhood, which was a confounding factor in finding the relation between parents with PTSD and PTSD in their children, was omitted. Salivary cortisol levels were obtained on awakening and at bedtime in 38 infants and their mothers, who had been directly exposed to the WTC collapse during pregnancy, at the 9-month examination of the infants. The levels were significantly lower in the offspring of women with PTSD than in those whose mothers had not developed PTSD. Interestingly, lower cortisol levels were most apparent in babies born to mothers with PTSD who were exposed in their third trimesters. The authors suggested that the similar findings observed in adult OHS were probably unrelated to their own traumatization or to poor parenting that occurred immediately after the postnatal period. ${ }^{31}$ The importance of the perinatal period in programming and development of hormonal changes and resultant PTSD vulnerability, which might be specifically related to maternal factors, was considered. These findings underscore very early effects of maternal PTSD related to cortisol in offspring and highlight the relevance of in utero contributors to a putative biological risk for PTSD. Recently, a study was conducted on 126 mothers to ascertain whether correlations exist between maternal early-life sexual and physical abuse and both maternal and infant salivary cortisol levels during a laboratory stress paradigm at 6 months postpartum. Infants whose mothers had the history of trauma showed significantly lower baseline cortisol levels. This finding is in congruence with the evidence indicating that alterations in maternal cortisol levels would influence the HPA axis in offspring. ${ }^{32}$ Other studies, in turn, have indicated that maternal PTSD may reflect genetic or genetic-environmental interactions regulating individual differences in cortisol or cortisol responses to stress, which may be transmitted. ${ }^{33}$

\section{The unique maternal role}

A study of mean serum cortisol levels was conducted to characterize the patterns of basal cortisol secretion in OHS. ${ }^{26}$ In this study, cortisol secretion was measured every 30 minutes over a 24-h period. Subjects with current or lifetime PTSD were excluded, to focus on biological signals resulting from parental trauma exposure. Lower cortisol values were observed in offspring with parental PTSD as opposed to offspring of survivors without PTSD or comparison subjects. This effect was specifically related to the presence of maternal PTSD. ${ }^{26}$ This finding raised the possibility that the transmission of PTSD to the next generation is acquired via the mother, either through in utero exposures by alteration of glucocorticoid receptor sensitivity or in response to maternal behaviors in early life.

Looking into the concept of transgenerational transmission of PTSD, 284 communities recruited participants in a study designed to identify lifetime traumatic experience and psychiatric diagnoses. The analysis demonstrated that offspring with only paternal PTSD were not significantly different from offspring with no parental PTSD or comparison subjects in terms of mean cortisol release. On the other hand, mean cortisol release was similar in offspring where both parents suffered from PTSD and in those with only maternal PTSD. After controlling for the presence of PTSD in the other parent, only maternal PTSD retained its significant negative association with mean cortisol levels in offspring. ${ }^{34}$ These findings and the aforementioned evidence hypothesize that maternal PTSD might contribute in a unique manner to decreased cortisol levels in offspring. There was some postulation for this phenomenon.

\section{Programming}

The human HPA axis appears to be programmed by early-life influences, ${ }^{35,36}$ a phenomenon known as "HPA programming." ${ }^{37}$ It has been suggested that an alteration in glucocorticoid levels influences fetal brain development and, in doing so, programs the HPA axis. Reduced activity of placental 11-beta-hydroxycorticosteroid dehydrogenase type 2, the enzyme that catalyzes the conversion of maternal cortisol to cortisone, may result in an increased exposure of the fetus to glucocorticoids and may contribute to HPA axis programming. ${ }^{38}$ It has also been suggested that low cortisol levels in offspring could be mediated by alterations in glucocorticoid receptor sensitivity. ${ }^{39}$

Stress-related gene expression or the effect of in utero stress on the neurobiology of PTSD might also be responsible. ${ }^{30}$ Epigenetics refers to a transgenerationally transmissible functional change in the genome that can be altered by environmental events and does not involve an alteration of DNA structure. Epigenetic changes can completely silence a gene or, depending on their directionality, otherwise diminish or augment gene expression. For instance, an environmental exposure may alter glucocorticoid gene methylation, and as a result, the function of the gene will change; this then biases the individual's response to a subsequent traumatic event. ${ }^{40,41}$ DNA methylation is known a mechanism for programming of the activity of genes regulating HPA activity by early-life events. ${ }^{30,42}$

While some previous studies have implicated maternal and paternal trauma exposure as significant predictors of PTSD in offspring, ${ }^{43,44}$ a recent study emphasized the unique role of the mother in transmission of PTSD to the next generation. ${ }^{34}$ Therefore, a conceptualization of the evidence may be that both parents equally contribute the genetic component or collectively influence the environmental aspects. However, epigenetic mechanisms and HPA programming are sufficient to explain the preferential contribution of maternal PTSD to offspring PTSD risk. $^{45}$

\section{A glance at non-biological evidence}

There is also some non-biological evidence that confirms the transgenerational transmission of extraordinary traumatic effects on clinical populations. In a review of 35 
studies on the transgenerational effect of the Holocaust, the authors reported a difference between clinical and non-clinical populations. There was no difference between non-clinical OHS and the general population in psychopathology. The authors speculated that only subgroups of OHS would develop psychopathology. ${ }^{46}$ These include offspring born early after parental trauma, firstborn children, offspring whose parents were both survivors, cases in which the trauma was discussed too little or too much in the family, etc. Similar results were repeated in other studies. ${ }^{47-49}$ These findings are indicative of the prominence of psychopathology in offspring of patients with clinical PTSD.

\section{Discussion}

In summary, there is some biological evidence of transgenerational transmission of PTSD vulnerability, mostly related to maternal factors. Probable mechanisms include: HPA programming or alterations in gene expression under direct influence of maternal biological factors, such as cortisol levels during pregnancy; and a change in HPA system attributable to parental behavior, occurring early in life.

In addition to these mechanisms, some other possible mechanisms of transgenerational transmission of PTSD vulnerability have been proposed, which are not directly within the scope of this paper. These include: 1) genetic polymorphisms that decrease the threshold for developing PTSD directly or indirectly via genetically influenced temperament, increasing the risk of exposure to trauma ${ }^{50-62}$; and 2) learning the symptoms of PTSD in childhood via interactions with PTSD parents and formation of cognitive schema which enhance a subjective perception of threat that could lead to PTSD development. Cognitive schema such as "the world is dangerous" could make the psychological structure of the mind perceive traumatic events as more hazardous and catastrophic than they actually are ${ }^{16} ; 3$ ) being traumatized by trauma-related stories per se or by visualizing what their parents experienced has also been described as a risk factor for subsequent trauma exposure and for PTSD in offspring of patients with PTSD. ${ }^{63}$

Despite the benefits of the scientific findings of the studies reviewed in the current paper, some limitations need to be addressed. First, the sample sizes of most studies were not large enough. Second, most of these samples comprised a specific type of patients with a particular trauma, namely, Jewish victims of the Holocaust. Thus, the aforementioned results could well be generalized to Holocaust survivors, and these findings should be studied in more detail in other types of trauma with different severities and other populations with a variety of genetic backgrounds. Survivors of the recent tsunami in Southeast Asia and of the earthquakes of Tabas (Iran), Japan, Pakistan, and Turkey seem to be reasonable cases for further investigation. Third, most of these studies were the outcome of very few research groups. Conducting similar studies with other research teams might strengthen the available evidence (Table 1). Finally, there are some paradoxical findings in the literature, mostly related to cortisol levels in PTSD. Although several studies report decreased plasma, urine, or salivary cortisol levels in PTSD, some studies did not, ${ }^{64-70}$ and others have even reported an increase in cortisol levels in bodily fluids. ${ }^{71} \mathrm{~A}$ meta-analysis found that across 37 studies, 828 people with PTSD were no different from 800 controls in terms of cortisol levels. However, after examining the type of trauma, the subgroup of PTSD patients with a history of physical or sexual abuse had significantly lower cortisol levels than controls. Hence, the authors postulated that low cortisol levels in PTSD are only found under certain conditions. ${ }^{72}$ According to these findings, the possibility of a decrease in cortisol levels in the next generation and the effect of low cortisol levels on HPA programming can be called into question.

We believe that similar studies should be conducted in other countries with different genetic backgrounds and larger sample sizes to strengthen the current literature. Increasing the number of studies with robust methodological quality and larger sample sizes should omit possible biases.

A good opportunity for research on transgenerational transmission of PTSD now exists in Iran. Twenty-three years have passed since the end of the Iraq-Iran war. More than 200,000 traumatized individuals currently suffer the consequences of this war inside Iran, and probably a similar number in Iraq. The offspring of these individuals are now in adulthood and their parents may still be alive. This large, two-generation sample would be a suitable study population for investigations into the transgenerational transmission of PTSD vulnerability.

Table 1 Studies providing the most important non-genetic biological evidence of transgenerational transmission of PTSD in humans

\begin{tabular}{llccrc}
\hline $\begin{array}{l}\text { Year of } \\
\text { publication }\end{array}$ & First author & $\begin{array}{c}\text { Cause of } \\
\text { parental PTSD }\end{array}$ & $\begin{array}{c}\text { Number of offspring } \\
\text { with PTSD parents }\end{array}$ & Fluid sample & Biological marker \\
\hline 2000 & Rachel Yehuda & Holocaust & 35 & Urine & Cortisol \\
2001 & Rachel Yehuda & Holocaust & 51 & Urine & Cortisol \\
2002 & Rachel Yehuda & Holocaust & 39 & Crine & Saliva \\
2005 & Rachel Yehuda & World Trade Center collapse & 38 & Cortisol \\
2007 & Rachel Yehuda & Holocaust & 13 & Plasma & Cortisol \\
2007 & Rachel Yehuda & Holocaust & 23 & Plasma & Cortisol \\
2010 & Sarah R. Brand & Maternal childhood abuse & 126 & Saliva & Cortisol \\
\hline
\end{tabular}




\section{Disclosure}

The authors report no conflicts of interest.

\section{References}

1 Turnbull GJ. A review of post-traumatic stress disorder. Part I: Historical development and classification. Injury. 1998;29:87-91.

2 Zarghami M. [Validity of PTSD Criteria in Mazandaran veterans]. J Mazandaran Univ Med Sci. 1992;1:15-25.

3 Sanati M, Zarghami M, Keshoufi M. [Anxiety features in PTSD veterans]. J Facul Med. 1991;49:43-55.

4 Sanati M, Zarghami M. Kashoufi M. [Depression in chronic combat reaction]. J Facul Med. 1995;53:75-8.

5 Zarghami M, Khalilian AR, Tirgari A, Khoshsorour H, Rezai AN. [An epidemiological study of psychiatric disorders in veterans in Iran]. $J$ Mazandaran Univers Med Sci. 1998;7-8:25-32.

6 Zarghami M, Ghaffari Saravi V. [PTSD in cancerous children]. J Mazandaran Univers Med Sci. 1993;2:20-3.

7 Breslau N, Kessler RC, Chilcoat HD, Schultz LR, Davis GC, Andreski $P$. Trauma and posttraumatic stress disorder in the community: the 1996 Detroit Area Survey of Trauma. Arch Gen Psychiatry. 1998;55;626-32.

8 Kessler RC, Sonnega A, Bromet E, Hughes M, Nelson CB. Posttraumatic stress disorder in the National Comorbidity Survey. Arch Gen Psychiatry. 1995;52;1048-60.

9 Kulka RA, Fairbank JA, Jordan BK. Trauma and the Vietnam war generation: report of findings from the National Vietnam Veterans Readjustment Study. New York: Brunner/Mazel; 1990.

10 Resnick HS, Kilpatrick DG, Dansky BS, Saunders BE, Best CL. Prevalence of civilian trauma and posttraumatic stress disorder in a representative national sample of women. J Consult ClinPsychol. 1993;61:984-91.

11 Ashtarani Z, Zarghami M, Khalilian AR. [Barresie pi ti es di dar nejat yaftegan as soukhtegi]. Sari: Mazandaran University of Medical Sciences; 1995

12 Perkonigg A, Kessler RC, Storz S, Wittchen HU. Traumatic events and posttraumatic stress disorder in the community: Prevalence, risk factors, and comorbidity. Acta Psychiatr Scand. 2000;101:46-59.

13 Davidson JR, Stein DJ, Shalev AY, Yehuda R. Post-traumatic stress disorder: acquisition, recognition, course, and treatment. J Neuropsychiatry Clin Neurosci. 2004;16:135-47.

14 McFarlane AC. Posttraumatic stress disorder: a model of the longitudinal course and the role of risk factors. J Clin Psychiatry. 2000;61:15-20.

15 Zarghami M. [Role of symptoms in prognosis of PTSD (a proposed hypothesis)]. J Mazandaran Univers Med Sci. 1994;3:40-53.

16 Yehuda R, Bierer LM. Transgenerational transmission of cortisol and PTSD risk. Prog Brain Res. 2008;167:121-35.

17 Yehuda R, Schmeidler J, Giller EL Jr, Siever LJ, Binder-Brynes K. Relationship between posttraumatic stress disorder characteristics of Holocaust survivors and their adult offspring. Am J Psychiatry, 1998; 155:841-3.

18 Yehuda R, Schmeidler J, Wainberg M, Binder-Brynes K, Duvdevani T. Vulnerability to posttraumatic stress disorder in adult offspring of Holocaust survivors. Am J Psychiatry. 1998;155:1163-71.

19 Mason JW, Giller EL, Kosten TR, Ostroff RB, Podd L. Urinary freecortisol levels in posttraumatic stress disorder patients. J Nerv Ment Dis. 1986;174:145-9.

20 Boscarino J A. Posttraumatic stress disorder, exposure to combat, and lower plasma cortisol among Vietnam veterans - findings and clinical implications. J Consult Clin Psychol. 1996;64:191-201.

21 Resnick HS, Yehuda R, Pitman RK, Foy DW. Effect of previous trauma on acute plasma cortisol level following rape. Am J Psychiatry. 1995;152:1675-7.

22 Delahanty DL, Raimonde AJ, Spoonster E, Cullado M. Injury severity, prior trauma history, urinary cortisol levels, and acute PTSD in motor vehicle accident victims. J Anxiety Disord. 2003;17:149-64.

23 Yehuda R. Current status of cortisol findings in post-traumatic stress disorder. Psychiatr Clin North Am. 2002;25:341-68.
24 Yehuda R, Bierer LM, Schmeidler J, Aferiat DH, Breslau I, Dolan S. Low cortisol and risk for PTSD in adult offspring of holocaust survivors. Am J Psychiatry. 2000;157:1252-9.

25 Yehuda R, Halligan SL, Bierer LM. Cortisol levels in adult offspring of Holocaust survivors: relation to PTSD symptom severity in the parent and child. Psychoneuroendocrinology. 2002;27:171-80.

26 Yehuda R, Teicher MH, Seckl JR, Grossman RA, Morris A, Bierer LM. Parental posttraumatic stress disorder as a vulnerability factor for low cortisol trait in offspring of holocaust survivors. Arch Gen Psychiatry. 2007;64:1040-8.

27 Yehuda R, Blair W, Labinsky E, Bierer LM. Effects of parental PTSD on the cortisol response to dexamethasone administration in their adult offspring. Am J Psychiatry. 2007:164:163-6.

28 Yehuda R, Halligan SL, Grossman R. Childhood trauma and risk for PTSD: relationship to intergenerational effects of trauma, parental PTSD, and cortisol excretion. Dev Psychopathol. 2001;13:733-53.

29 Gunnar MR, Vazquez DM. Low cortisol and a flattening of expected daytime rhythm: potential indices of risk in human development. Dev Psychopathol. 2001;13:515-38.

30 Yehuda R, Bierer LM. The relevance of epigenetics to PTSD: implications for the DSM-V. J Trauma Stress. 2009;22:427-34.

31 Yehuda R, Engel SM, Brand SR, Seckl J, Marcus SM, Berkowitz GS Transgenerational effects of posttraumatic stress disorder in babies of mothers exposed to the World Trade Center attacks during pregnancy. J Clin Endocrinol Metab. 2005;90:4115-8.

32 Brand SR, Brennan PA, Newport DJ, Smith AK, Weiss T, Stowe ZN The impact of maternal childhood abuse on maternal and infant HPA axis function in the postpartum period. Psychoneuroendocrinology. 2010;35:686-93.

33 Bartels M, Van den Berg M, Sluyter F, Boomsma DI, de Geus EJ. Heritability of cortisol levels: review and simultaneous analysis of twin studies. Psychoneuroendocrinology. 2003;28:121-37.

34 Yehuda R, Bell A, Bierer LM, Schmeidler J. Maternal, not paternal, PTSD is related to increased risk for PTSD in offspring of Holocaus survivors. J Psychiatr Res. 2008:42:1104-11.

35 Francis DD, Caldji C, Champagne F, Plotsky PM, Meaney MJ. The role of corticotropin-releasing factor - norepinephrine systems in mediating the effects of early experience on the development of behavioural and endocrine responses to stress. Biol Psychiatry. 1999:46:1153-66.

36 Weaver IC, Szyf M, Meaney MJ. From maternal care to gene expression: DNA methylation and the maternal programming of stress responses. Endocr Res. 2002;28:699.

37 Seckle JR, Meaney MJ. Glucocorticoid "programming" and PTSD risk. Ann N Y Acad Sci. 2006;1071:351-78.

38 Seckl JR. Prenatal glucocorticoids and long-term programming. Eur J Endocrinol. 2004;151:U49-62.

39 Mathews SG. Early programming of the hypothalamo-pituitaryadrenal axis. Trends Endocrinol Metab. 2002;13:373-80.

40 Meaney MJ, Szyf M. Environmental programming of stress responses through DNA methylation: life at the interface between a dynamic environment and a fixed genome. Dialogues Clin Neurosci. 2005;7:103-23.

41 Sutherland JE, M Costa. Epigenetics and the environment. Ann N Y Acad Sci. 2003:983:151-60.

42 Weaver IC, Cervoni N, Champagne FA, D'Alessio AC, Sharma S, Seckl JR, et al. Epigenetic programming by maternal behavior. Nat Neurosci. 2004;7:847-54.

43 DijanićPlasćl, Peraica T, Grubisić-llić M, Rak D, JambrosićSakoman A, Kozarić-Kovacić D. Psychiatric heredity and PTSD: survey study of war veterans. Croat Med J. 2007;48:146-56.

44 Meijer A. Child psychiatric sequelae of maternal war stress. Acta Psychiatr Scand. 1985;72:505-11.

45 Maurel MC, Kanellopoulos-Langevin C. Heredity -- Venturing beyond genetics. Biol Reprod. 2008:79:2-8.

46 Kellerman NP. Psychopathology in children of Holocaust survivors: a review of the research literature. Isr J Psychiatry Relat Sci. 2001;38:36-46.

47 van IJzendoorn MH, Bakermans-Kranenburg MJ, Sagi-Schwartz A Are children of Holocaust survivors less well-adapted? A metaanalytic investigation of secondary traumatization. J Trauma Stress. 2003:16:459-69.

48 Sagi-Schwartz A, Van IJzendoorn MH, Grossmann KE, Joels T, Grossmann K, Scharf M, et al. Attachment and traumatic stress in 
female holocaust child survivors and their daughters. Am J Psychiatry. 2003;160:1086-92.

49 Sagi-Schwartz A, van IJzendoorn MH, Bakermans-Kranenburg MJ. Does intergenerational transmission of trauma skip a generation? No meta-analytic evidence for tertiary traumatization with third generation of Holocaust survivors. Attach Hum Dev. 2008;10:105-21.

50 True WJ, Rice J, Eisen SA, Heath AC, Goldberg J, Lyons MJ, et al. A twin study of genetic and environmental contributions to liability for posttraumatic stress symptoms. Arch Gen Psychiatry. 1993;50:25764.

51 Skre I, Onstad S, Torgesen S, Lygren S, Kringlen E. A twin study of DSM-III-R anxiety disorders. Acta Psychiatr Scand. 1993;88:85-92.

52 Koenen KC, Harley R, Lyons MJ, Wolfe J, Simpson JC, Goldberg J, et al. A twin registry study of familial and individual risk factors for trauma exposure and posttraumatic stress disorder. J NervMent Dis. 2002;190:209-18.

53 Lyons MJ, Goldberg J, Eisen SA, True W, Tsuang MT, Meyer JM, et al. Do genes influence exposure to trauma? A twin study of combat. Am J Med Genet. 1993;48:22-7.

54 Stein MB, Jang KL, Taylor S, Vernon PA, Livesley WJ. Genetic and environmental influences on trauma exposure and posttraumatic stress disorder symptoms: a twin study. Am J Psychiatry. 2002;159:1675-81.

55 Broekman BF, Olff M, Boer F. The genetic background to PTSD. Neurosci Biobehav Rev. 2007;31:348-62.

56 Segman RH, Shalev AY. Genetics of posttraumatic stress disorder. CNS Spectr. 2003;8:693-8.

57 Bachmann AW, Sedgley TL, Jackson RV, Gibson JN, Young RM, Torpy DJ. Glucocorticoid receptor polymorphisms and post-traumatic stress disorder. Psychoneuroendocrinology. 2005;30:297-306.

58 Amstadter AB, Nugent NR, Koenen KC. Genetics of PTSD: fear conditioning as a model for future research. Psychiatr Ann. 2009:39:358-67.

59 Nugent NR, Amstadter AB, Koenen KC. Genetics of post-traumatic stress disorder: informing clinical conceptualizations and promoting future research. Am J Med Genet C Semin Med Genet. 2008;148C:127-32.

60 Yehuda R, Koenen KC, Galea S, Flory JD. The role of genes in defining a molecular biology of PTSD. Dis Markers. 2011;30:67-76.
61 Kremen WS, Koenen KC, Afari N, Lyons MJ. Twin studies of posttraumatic stress disorder: differentiating vulnerability factors from sequelae. Neuropharmacology. 2012;62:647-53.

62 Amstadter AB, Nugent NR, Koenen KC. Genetics of PTSD: fear conditioning as a model for future research. Psychiatr Ann. 2009;39:358-67.

63 Koenen KC. Moffitt TE, Poulton R, Martin J, Caspi A. Early childhood factors associated with the development of post-traumatic stress disorder: results from a longitudinal birth cohort. Psychol Med. 2007;37:181-92.

64 Mason JW, Giller EL, Kosten TR, Ostroff RB, Podd L. Urinary free cortisol levels in post traumatic stress disorder patients. J Nerv Ment Dis. 1986;174:145-9.

65 Yehuda R, Kahana B, Binder-Brynes K, Southwick SM, Mason JW, Giller EL. Low urinary cortisol excretion in Holocaust survivors with posttraumatic stress disorder. Am J Psychiatry. 1995;152:982-6.

66 Yehuda R. Biology of posttraumatic stress disorder. J Clin Psychiatry. 2001;62:41-6.

67 Liberzon I, Abelson JL, Flagel SB, Raz J, Young EA. Neuroendocrine and psychophysiologic responses in PTSD: a symptom provocation study. Neuropsychopharmacology. 1999;21:40-50.

68 Pitman RK, Orr SP. Twenty-four hour urinary cortisol and catecholamine excretion in combat-related posttraumatic stress disorder. Biol Psychiatry. 1990;27:245-7.

69 Lemieux AM, Coe CL. Abuse-related posttraumatic stress disorder: evidence for chronic neuroendocrine activation in women. Psychosom Med. 1995;57:105-15.

70 De Bellis MD, Baum AS, Birmaher B, Keshavan MS, Eccard CH, Boring AM, et al. A.E. Bennett Research Award. Developmental traumatology. Part I: biological stress systems. Biol Psychiatry. 1999;45:1259-70.

71 Maes M, Lin A, Bonaccorso S, van Hunsel F, Van Gastel A, Delmeire $L$, et al. Increased 24-hour urinary cortisol excretion in patients with post-traumatic stress disorder and patients with major depression, but not in patients with fibromyalgia. Acta Psychiatr Scand. 1998;98:328-35.

72 Meewisse ML, Reitsma JB, de Vries GJ, Gersons BP, Olff M. Cortisol and post-traumatic stress disorder in adults: systematic review and meta-analysis. Br J Psychiatry. 2007;191:387-92. 